\title{
Birth desires and intentions of women diagnosed with a meningioma
}

\author{
Michelle A. Owens, MA, ${ }^{1}$ Benjamin M. Craig, PhD, ${ }^{1,2}$ Kathleen M. Egan, ScD, ${ }^{3}$ \\ and Damon R. Reed, MD4 \\ ${ }^{1}$ Health Outcomes and Behavior, Moffitt Cancer Center; ${ }^{2}$ Department of Economics, University of South Florida; and ${ }^{3}$ Cancer \\ Epidemiology and ${ }^{4}$ Sarcoma Program, Moffitt Cancer Center, Tampa, Florida
}

\begin{abstract}
OBJECT To the authors' knowledge, no previous study has examined the impact of meningioma diagnosis on women's birth desires and intentions. In an exploratory study, the authors surveyed women affected by meningioma to determine their attitudes toward childbearing and the influences, including physician recommendations, on this major life decision and compared their responses to those of women in the general population.

METHODS Meningioma survivors from the Meningioma Mommas online support group participated in an online survey that included questions on their birth desires and intentions, whether the risk of disease recurrence influenced their reproductive decisions, and risks communicated to them by their physicians. Using chi-square and rank-sum tests, the authors compared the survey participants' responses with those of the general population as assessed by the 20062010 National Survey of Family Growth. Logistic regression was used to adjust for differences in age, race, ethnicity, education, parity, pregnancy status, and infertility status in these populations.
\end{abstract}

RESULTS Respondents with meningioma were more likely than those in the general population to report wanting a baby ( $70 \%$ vs $54 \%$, respectively), intending to have a baby ( $27 \%$ vs $12 \%$, respectively), and being very sure about this intention ( $10 \%$ vs $2 \%$, respectively). More than half (32 of 61) of the women of childbearing age reported being advised by a physician about potential risk factors for recurrence of the meningioma, and pregnancy was the most commonly cited risk factor (26 of 61$)$. The most common factor influencing birth desires and intentions was risk of the meningioma returning and requiring more treatment, which was reported by nearly two-thirds of the women in their childbearing years.

CONCLUSIONS A majority of the meningioma survivors of childbearing age who completed the survey reported a desire for children, although concern about the risk of meningioma recurrence was an important factor for these women when making reproductive decisions. Physicians are in a position to educate their patients on potential risk factors for recurrence and to provide contact information for services such as counseling and family planning.

http://thejns.org/doi/abs/10.3171/2014.11.JNS14522

KEY WORDS meningioma; birth; pregnancy; National Survey of Family Growth; oncology

$\mathrm{M}$ ENINGIOMAS are the most common primary brain tumor, ${ }^{30}$ comprising nearly $34 \%$ of CNS tumors, with an age-adjusted incidence rate of approximately 5.04 per 100,000 US women ${ }^{7}$ and a prevalence rate of 97.5 in 100,000 US adults overall..$^{7,29}$ The incidence rate for meningiomas in women is nearly twice that of men,$^{30}$ with an even greater differential observed during the reproductive years. ${ }^{32}$ These tumors are generally slow growing, and only $2 \%-3 \%$ of them are classified as malignant. ${ }^{3}$ Depending on their size and location, meningio- mas may remain undetected; ${ }^{27}$ common symptoms include headache, seizures, changes in vision or hearing, focal weakness, and dizzy spells., Given the higher incidence during pregnancy, many physicians and researchers have long speculated that pregnancy may cause or increase the chance of developing a meningioma or its recurrence, particularly because of the increase in progesterone during pregnancy. ${ }^{20}$

Some women may question whether to become pregnant after being diagnosed with a meningioma. The risk

ABBREVIATIONS MMS = Meningioma Momma Survey; NSFG = National Survey of Family Growth.

SUBMITTED March 18, 2014. ACCEPTED November 4, 2014

INCLUDE WHEN CITING Published online January 27, 2015; DOI: 10.3171/2014.11.JNS14522.

DISCLOSURE The authors report no conflict of interest concerning the materials or methods used in this study or the findings specified in this paper. Funding for this study was provided by the National Cancer Institute (grant no. 1R01CA160104 awarded to Dr. Craig). Dr. Craig was also supported by the Moffitt Cancer Center. 
of recurrence or progression may affect the birth desires and intentions of women who have been diagnosed with a meningioma because of the possible effects of pregnancy on risk and the added challenges of symptoms and treatment during motherhood. However, delaying or avoiding pregnancy can have a psychological impact on a woman's life. In a recent article, Craig et al. ${ }^{9}$ reported that at 39 years of age, $73 \%$ of childless women wanted a baby but only $7 \%$ would have one. It is likely that, for some women, the possible or perceived risk of meningioma recurrence with pregnancy outweighs the psychological cost of delaying or avoiding pregnancy. Despite multiple studies that have examined risk factors for developing a meningioma, $2,4,6,8,10,11,15,18,21,24,33$ no study has examined women's birth desires and intentions after a meningioma diagnosis.

In addition to the patient's own assessment of risks and benefits of parity after meningioma, a physician may advise against pregnancy despite the patient's desire for children because of the perceived risk of tumor recurrence. Although a few studies have shown a modest correlation between parity and meningioma occurrence, ${ }^{23,32}$ there are currently no data informing the question of whether pregnancy induces meningioma recurrence. However, the general perception of risk may influence reproductive choices in affected women depending, in part, on physicians' knowledge and advice. To our knowledge, no study has examined the role of patient perceptions and physician advice on the reproductive choices of women of childbearing age with a diagnosis of meningioma.

In this exploratory study, we examined the following: 1) whether the diagnosis of meningioma in women of childbearing age affected their birth desires and intentions when compared with women in the general population, 2) whether physicians cautioned against childbearing in these women, 3) whether concerns surrounding the risk of tumor recurrence influenced birth desires and intentions, and 4) what factors were most influential in those reproductive decisions.

\section{Methods}

\section{Participants}

Respondents were recruited to participate in an online survey through the Meningioma Mommas organization, a not-for-profit online support group and discussion board (http://www.meningiomamommas.org/home) founded in 2003 for women affected by meningioma. Participants were recruited in the two following ways: via a banner advertisement posted on the Meningioma Mommas website that provided access to the survey and via direct email from the organization's founder to the Meningioma Mommas blog members that included a link to the survey. Upon providing consent, each participant completed a screener to ensure that she met the following inclusion criteria: age 18 years or older, current US resident, and currently or previously diagnosed with a meningioma. Respondents (Table 1) were not compensated for participation and could withdraw from the survey at any time by closing the browser. Data were collected from September 20, 2013, to January 16, 2014, and all procedures were approved by the University of South Florida Institutional Review Board.

\section{Meningioma Mommas Survey Instrument}

The Meningioma Mommas Survey (MMS) instrument included the following 6 sections: screener (consent form); meningioma diagnosis and treatment; pregnancy and children; birth desires and intentions; risk of meningioma recurrence; and health, household, and survey experience. Each question required an answer.

The MMS included the birth desires and intentions component of the National Survey of Family Growth (NSFG), which adapts to pregnancy and infertility question responses. ${ }^{22}$ Specifically, each participant was asked whether she wants to have a baby. If so, she was asked whether she intends to have a baby and, if so, how many children she intends to have and whether she is sure about this intention (Table 2). Furthermore, the survey asked, "Does risk of meningioma recurrence influence any of the following birth desires and intentions? Check all that apply" and "Which factors influenced your birth desires and intentions? Check all that apply" (Tables 3 and 4). If the participant chose "other," she was directed to an open-text box in which she could enter other influential factors.

To assess risk factors communicated by physicians to their patients, participants were asked, "Has a doctor ever told you that any of the following factors are related to risk of meningioma recurrence? Check all that apply," which was followed by a list of potential risk factors for meningioma $^{2,711,24,31}$ (Table 5). The survey took approximately 15 minutes to complete, and the last question included an open-text box for general comments. Screenshots of the survey instrument are available online (http://labpages. moffitt.org/craigb/Surveys/Surveys.html [http://labpages. moffitt.org/craigb/Surveys/MMScrnShts_130822.pdf]).

\section{National Survey of Family Growth}

Participant characteristics (Table 1) and birth desires and intentions were compared with those from the NSFG, a cross-sectional survey of women and men aged 15-44 years conducted by the University of Michigan's Institute of Social Research from June 2006 to June 2010, under contract with the National Center for Health Statistics. ${ }^{12}$ The NSFG included participants from a variety of metropolitan and nonmetropolitan areas across the US who were selected to approximate the 2000 Census population. Interviewers visited housing units from designated geographical areas to determine eligibility (ages $15-44$ years). If more than one eligible person lived in the household, the interviewer randomly selected one participant. Unlike an online survey, the NSFG was administered face-toface by trained female interviewers from the University of Michigan's Institute of Social Research, who collected data on a variety of topics, including, marriage, pregnancy, contraception, fertility treatment, and health. ${ }^{12,19}$

\section{Statistical Analysis}

At a significance level of 0.05 , differences in the frequency of categorical responses were tested using chisquare tests, and differences in age and number of children were tested using rank-sum tests. In Table 2, we present the results of 4 logistic regressions using the combined sample (MMS and NSFG, ages 25-44 years) adjusted for age, race and ethnicity, education, parity, pregnancy status, 
TABLE 1. Respondent characteristics in the MMS and NSFG

\begin{tabular}{|c|c|c|c|c|}
\hline \multirow[b]{2}{*}{ Respondent Characteristic } & \multirow[b]{2}{*}{ All Ages, MMS $(n=121)$} & \multicolumn{2}{|c|}{ Ages 25-44 Yrs } & \multirow[b]{2}{*}{ p Value* } \\
\hline & & MMS $(n=61)$ & NSFG $(n=7889)$ & \\
\hline Age (median [IQR]) (yrs) & $44(38-54)$ & $38(34-41)$ & $33(29-39)$ & $<0.001$ \\
\hline \multicolumn{5}{|l|}{ Race/ethnicity (no. [\%]) } \\
\hline Hispanic & $3(2.48)$ & $2(3.28)$ & $1753(22.22)$ & $<0.001$ \\
\hline Non-Hispanic white & $114(94.21)$ & $57(93.44)$ & $4084(51.77)$ & \\
\hline Non-Hispanic black & $1(0.83)$ & $0(0)$ & $1595(20.22)$ & \\
\hline Non-Hispanic other & $3(2.48)$ & $2(3.28)$ & $457(5.79)$ & \\
\hline \multicolumn{5}{|l|}{ Education (no. [\%]) } \\
\hline High school or less & $11(9.09)$ & $5(8.2)$ & $2983(37.81)$ & $<0.001$ \\
\hline Some college & $34(28.1)$ & $18(29.51)$ & $2663(33.76)$ & \\
\hline Undergraduate degree & $41(33.88)$ & $25(40.98)$ & $1564(19.83)$ & \\
\hline Graduate degree & $35(28.93)$ & $13(21.31)$ & $679(8.61)$ & \\
\hline \multicolumn{5}{|l|}{ Parity (median [IQR]) } \\
\hline No. of children & $2(1-3)$ & $2(1-3)$ & $2(0-3)$ & 0.007 \\
\hline Age of youngest child (yrs) & $9(4-19)$ & $4(2-6)$ & $5(2-9)$ & 0.132 \\
\hline \multicolumn{5}{|l|}{ Pregnancy status (no. [\%]) } \\
\hline Currently pregnant & $1(0.83)$ & $1(1.64)$ & $315(3.99)$ & 0.059 \\
\hline Previously pregnant & $103(85.12)$ & $54(88.52)$ & $5947(75.38)$ & \\
\hline Never pregnant & $17(14.05)$ & $6(9.84)$ & $1627(20.62)$ & \\
\hline Infertile status (no. [\%]) & $42(34.71)$ & $5(8.2)$ & $1979(25.09)$ & 0.002 \\
\hline
\end{tabular}

* Rank-sum test and chi-square test results comparing MMS and NSFG characteristics among women 25-44 years of age.

and infertility status. The null case for each logistic regression was a 35-year-old non-Hispanic white woman who is fertile, is not pregnant, has an undergraduate degree, and has a 5-year-old child. No sampling weights were available to improve the generalizability of the subsets of analytical files.

\section{Results}

Of the 162 MMS participants who provided consent for study participation, 146 completed the screener, 138 were eligible to continue ( 2 reported that they were never diagnosed with a meningioma and 6 were outside the US), and 121 completed the survey (17 dropped out). Among the 121 respondents, $79(65 \%)$ were first diagnosed with a lowgrade meningioma, $8(7 \%)$ were diagnosed with an intermediate-grade meningioma, and 34 (28\%) were unsure of the tumor grade. Of the 20 respondents who experienced 1 or 2 (14\% and 3\%, respectively) recurrences, $20(100 \%)$ reported having surgery, and $7(35 \%)$ reported undergoing radiation therapy. Among the 101 (83\%) respondents who did not experience recurrence, 66 had only surgery, 5 received only radiation therapy, 8 underwent surgery and radiation therapy, and 22 did not receive surgery or radiation therapy.

Of the 121 respondents who completed the survey, 61 were 25-44 years of age, which was the focus demographic of the analysis. The MMS participants were significantly older, more educated, and more likely to be fertile and had more children than those in the NSFG, and they were predominantly white and non-Hispanic (Table 1).

Approximately half of the MMS respondents (42\%) reported that their physician told them about at least 1 of the 11 risk factors for meningioma recurrence listed in the survey (Table 5). Although the risk factors were shown in random order, 2 factors were highly prevalent, pregnancy $(28 \%)$ and prescribed hormones $(25 \%)$. To a lesser degree, some participants reported radiography of the head $(12 \%)$ and head trauma (11\%) as risk factors. The remaining factors were rarely reported, if at all. Younger participants (ages 25-44 years) were more likely to report at least 1 factor, particularly pregnancy.

TABLE 2. Birth desires and intentions in women aged 25-44 years

\begin{tabular}{lccr}
\hline & \multicolumn{2}{c}{ \% Affirmative Responses } & \\
\cline { 2 - 3 } Birth Desire/Intention & MMS $(\mathrm{n}=61)$ & NSFG $(\mathrm{n}=7889)$ & $\mathrm{p}$ Value \\
\hline Wants to have a/another baby & 69.67 & 53.95 & 0.020 \\
\hline Intends to have a/another baby & 27.06 & 12.04 & 0.015 \\
\hline Very sure about birth intention & 9.70 & 2.17 & $<0.001$ \\
\hline Intends to have $>1$ baby & 6.10 & 3.44 & 0.384 \\
\hline
\end{tabular}

* Logistic regression estimates were adjusted for age, race and ethnicity, education, parity, pregnancy status, and infertility status with a null case of a 35-year-old non-Hispanic white woman who is fertile and not pregnant and has an undergraduate degree and a 5-year-old child. 
TABLE 3. Influence of meningioma recurrence on birth desires and intentions*

\begin{tabular}{|c|c|c|c|}
\hline $\begin{array}{l}\text { Does Risk of Meningioma Recurrence Influence Any of the } \\
\text { Following Birth Desires \& Intentions? (Check all that apply) }\end{array}$ & $\begin{array}{l}\text { All Ages }(n=121) \\
\quad(\text { no. }[\%])\end{array}$ & $\begin{array}{l}\text { Ages } 25-44 \text { Yrs } \\
(n=61)(\text { no. }[\%])\end{array}$ & $p$ Value* \\
\hline Wants to have a/another baby & $29(23.97)$ & $26(42.62)$ & $<0.001$ \\
\hline Intends to have a/another baby & $25(20.66)$ & $24(39.34)$ & $<0.001$ \\
\hline Sure about birth intention & $25(20.66)$ & $25(40.98)$ & $<0.001$ \\
\hline How many more babies intended & $20(16.53)$ & $20(32.79)$ & $<0.001$ \\
\hline None of the above & $76(62.81)$ & $21(34.43)$ & $<0.001$ \\
\hline
\end{tabular}

* Chi-square test results comparing the influence of recurrence on birth desires and intentions.

To put birth desires and intentions of the sample into context, Table 2 compares the responses of younger participants (aged 25-44 years) to those of the general US population (NSFG) adjusted for age, race, ethnicity, education, parity, pregnancy status, and infertility status. Before adjustment, the results showed that a substantial portion of the younger participants (aged 25-44 years) wanted a baby (28 [46\%] of 61), and some intended to have one (9 [15\%]). After adjustment, the results showed that younger participants were more likely to want a baby (70\% vs 54\%), to intend to have a baby ( $27 \%$ vs $12 \%$ ), and to be very sure about their intentions (10\% vs $2 \%$ ) compared with those in the general population, respectively.

As shown in Table 3,24\% of all MMS participants indicated that the risk of recurrence had influenced their birth desires; the percentage among women aged 25-44 years was higher (43\%). When asked about the influence of specific factors, half of the respondents reported "none of the above," and half of them indicated at least 1 of 9 factors listed in the survey (Table 4). The most common factor was "risk of meningioma returning and needing more treatment" (36\%), followed by "risk of lasting symptoms or impairments" (26\%), "fear of dying" (18\%), and "medical advice against getting pregnant" (18\%).

\section{Discussion}

This study showed that the majority of women aged 25-44 years with a meningioma diagnosis and sampled from the Meningioma Mommas support group have a strong desire to have a child. With the use of the NSFG population for comparison, the results suggest that, after controlling for age, race and ethnicity, education, parity, pregnancy status, and infertility status, the desire of the MMS participants is stronger than that of the general population. These findings agree with exploratory evidence from cancer survivors, of whom $13 \%$ reported that having a previous diagnosis of cancer increased their desire to have a child. ${ }^{26}$

There are scant data on whether pregnancy induces the recurrence of meningioma. Whereas epidemiological studies do not support a role of pregnancy in the initial development of meningiomas, patients with preexisting meningiomas may first become symptomatic during pregnancy, although it is unknown whether the pregnancy itself is responsible. Although there have been case reports of meningiomas concurrent with pregnancy, mainly from tertiary referral centers, ${ }^{5,16,17,25}$ pregnancy-associated meningioma is rare. Isla et al. ${ }^{13}$ recorded 2 cases of symptomatic meningioma in a series of 126,413 pregnancies. An estimated $90 \%$ of meningiomas are benign tumors (WHO Grade I), which are associated with a low risk of recurrence. ${ }^{28}$ We are not aware of any systematic studies on the relative or absolute risk of recurrence in pregnant women previously diagnosed with meningioma.

Physicians, spouses, friends, and family may influence a woman diagnosed with a meningioma for or against initial or subsequent pregnancy. Nearly half $(43 \%)$ of the MMS respondents aged 25-44 reported being told by a physician that pregnancy was a risk factor for recurrence, and approximately one-third (31\%) reported that "medical advice against pregnancy" influenced their birth desires

TABLE 4. Specific factors that influenced birth desires and intentions

\begin{tabular}{|c|c|c|c|}
\hline $\begin{array}{l}\text { Which Factors Influenced Your Birth Desires \& Intentions? } \\
\qquad \text { (Check all that apply) }\end{array}$ & $\begin{array}{l}\text { All Ages }(n=121) \\
\quad(\text { no. }[\%])\end{array}$ & $\begin{array}{l}\text { Ages } 25-44 \text { Yrs } \\
(n=61)(\text { no. }[\%])\end{array}$ & p Value* \\
\hline Risk of meningioma returning \& need for more treatment & $43(35.54)$ & $38(62.30)$ & $<0.001$ \\
\hline Risk of lasting symptoms or impairments & $31(25.62)$ & $27(44.26)$ & $<0.001$ \\
\hline Fear of dying & $22(18.18)$ & $21(34.43)$ & $<0.001$ \\
\hline Medical advice against getting pregnant & $22(18.18)$ & $19(31.15)$ & $<0.001$ \\
\hline Concern that the meningioma would harm pregnancy & $18(14.88)$ & $15(24.59)$ & 0.002 \\
\hline Concern that the meningioma could be "passed on" to my child & $11(9.09)$ & $11(18.03)$ & 0.001 \\
\hline Relationship difficulty as a result of diagnosis & $10(8.26)$ & $8(13.11)$ & 0.051 \\
\hline Family or friend advice against getting pregnant & $7(5.79)$ & $6(9.84)$ & 0.054 \\
\hline Other & $13(10.74)$ & $7(11.48)$ & 0.793 \\
\hline None of the above & $61(50.41)$ & $15(24.59)$ & $<0.001$ \\
\hline
\end{tabular}

* Chi-square test results comparing the influence of factors on birth desires and intentions. 
TABLE 5. Physician-patient communication of risk factors for meningioma recurrence

\begin{tabular}{lccr}
\hline $\begin{array}{l}\text { Has a Doctor Ever Told You That Any of the Following Factors Are } \\
\text { Related to Risk of Meningioma Recurrence? (Check all that apply) }\end{array}$ & $\begin{array}{c}\text { All Ages }(n=121) \\
(\text { no. }[\%])\end{array}$ & $\begin{array}{c}\text { Ages 25-44 Yrs } \\
(n=61)(n o . ~[\%])\end{array}$ & \begin{tabular}{c}
$p$ Value* \\
\hline Pregnancy
\end{tabular} \\
\hline Prescribed hormones & $34(28.1)$ & $26(42.62)$ & $<0.001$ \\
\hline X-ray study of the head & $15(12.4)$ & $8(13.11)$ & 0.712 \\
\hline Head trauma & $13(10.74)$ & $7(11.48)$ & 0.793 \\
\hline Family history & $7(5.79)$ & $4(6.56)$ & 0.714 \\
\hline Cell phone & $3(2.48)$ & $2(3.28)$ & 0.569 \\
\hline Smoking & $2(1.65)$ & $2(3.28)$ & 0.157 \\
\hline Allergies & $1(0.83)$ & $1(1.64)$ & 0.319 \\
\hline Alcohol consumption & $0(0)$ & $0(0)$ & 1.000 \\
\hline Diet & $0(0)$ & $0(0)$ & 1.000 \\
\hline Obesity & $0(0)$ & $0(0)$ & 1.000 \\
\hline None of the above & $70(57.85)$ & $29(47.54)$ & $<0.021$ \\
\hline
\end{tabular}

* Chi-square test results comparing communication of risk factors.

and intentions. It is also likely that some physicians are not aware of the strength of evidence regarding lifestyle and reproductive factors associated with meningioma recurrence or the general lack of research in this area and, therefore, fail to discuss risk factors with their patients, which makes it more difficult for patients to make informed decisions. One participant reported that "the lack of available information makes the decision to adopt, use a surrogate, or conceive naturally difficult to navigate."

According to the American Cancer Society, many physicians advise their patients with breast cancer not to become pregnant until 2 years after treatment, although currently there is a lack of evidence showing that pregnancy increases the risk for recurrence. ${ }^{1}$ In a large populationbased descriptive study, women who had previously been diagnosed with breast cancer were less likely to conceive than those in the general population, and those who did were more likely to give birth at a later age. ${ }^{14}$ In addition, those women who became pregnant within 2 years after diagnosis were more likely to terminate their pregnancy than those who became pregnant more than 2 years after the diagnosis ( $47 \%$ vs $21 \%$, respectively).

Fear of meningioma recurrence was by far the most common concern affecting family-planning decisions by women of reproductive age in the MMS study. More than half of those aged 25-44 years reported that the risk of recurrence influenced their birth desires and intentions. One participant commented that risk of the next "attack" would not be fair to her new child or husband. Another reported that she and her husband "gave up on his dream of becoming a father after her meningioma recurred." Other participants did not wish to go off their medications (mostly anticonvulsants that could cause birth defects). However, not all women were swayed by a fear of recurrence. One participant reported, "I decided not to let fear about my meningioma determine my family size, and even though my pregnancy might have increased the growth that led to surgery, I would still get pregnant again if I were younger."

The results of this study highlight the complexity of major reproductive decisions after therapy for a hormonepositive tumor. This situation is not limited to meningi- oma, as several other tumors, such as breast cancer and some types of sarcoma, have hormone receptor expression. A review of the literature indicates that studies to date have not conclusively measured the potential risk of subsequent pregnancy that could impact meningioma recurrence, which leads to uncertainty in the message that doctors convey to patients for real-world decision making.

This study has several limitations. First, the small sample of MMS participants was recruited from an online meningioma support group and may not be representative of the views and experiences of all women who have been diagnosed with a meningioma, including those without internet access. Second, approximately $96 \%$ of the respondents were non-Hispanic white women, and the results may not be generalizable to other racial/ethnic groups. However, this study may provide preliminary data for a larger patient-centered outcomes research study to assess whether pregnancy increases the risk of recurrence or symptoms. The results of such a study could be used to educate patients and physicians and to create an interactive decision-making tool for female meningioma survivors of childbearing age.

\section{Conclusions}

This project underscores the importance of reproductive decisions in younger women with meningioma, an often benign brain tumor but one that can significantly affect quality of life. The great majority of these women can expect long survival after definitive treatment for the tumors, but clear evidence on the possible risks associated with pregnancy is lacking. Physicians are in a position to educate patients on the state of knowledge and to provide information on services such as counseling and family planning to women in this age group who express a desire for children.

\section{Acknowledgments}

We greatly appreciate the external review comments from Dr. Gerald F. Tuite, pediatric neurosurgeon. We thank Carol Templeton, research program administrator, and Nawreen Jahan, 
research assistant, at Moffitt Cancer Center for their contributions to the research and creation of this paper; Liz Holzemer, founder of the Meningioma Mommas website; Jen Reed, meningioma patient advisor; and the Gonzmart Family Foundation for its continued support of the Moffitt Cancer Center Adolescent and Young Adult Program through research support and cancer awareness events.

\section{References}

1. American Cancer Society: Pregnancy after breast cancer. (http://www.cancer.org/cancer/breastcancer/detailedguide/ breast-cancer-after-pregnancy-after) [Accessed November 5, 2014]

2. Benson VS, Pirie K, Green J, Casabonne D, Beral V: Lifestyle factors and primary glioma and meningioma tumours in the Million Women Study cohort. Br J Cancer 99:185-190, 2008

3. Brain Science Foundation: Understand Primary Brain Tumors: Meningioma. (http://www.brainsciencefoundation. org/bUnderstandbPrimaryBrainTumors/Meningioma/tabid/ 186/Default.aspx) [Accessed November 5, 2014]

4. Cea-Soriano L, Blenk T, Wallander MA, Rodríguez LAG: Hormonal therapies and meningioma: is there a link? Cancer Epidemiol 36:198-205, 2012

5. Chow MS, Mercier PA, Omahen DA, Wood SL, Johnson JA: Recurrent exophytic meningioma in pregnancy. Obstet Gynecol 121 (2 Pt 2 Suppl 1):475-478, 2013

6. Claus EB, Black PM, Bondy ML, Calvocoressi L, Schildkraut JM, Wiemels JL, et al: Exogenous hormone use and meningioma risk: what do we tell our patients? Cancer 110:471-476, 2007

7. Claus EB, Bondy ML, Schildkraut JM, Wiemels JL, Wrensch M, Black PM: Epidemiology of intracranial meningioma. Neurosurgery 57:1088-1095, 2005

8. Claus EB, Walsh KM, Calvocoressi L, Bondy ML, Schildkraut JM, Wrensch M, et al: Cigarette smoking and risk of meningioma: the effect of gender. Cancer Epidemiol Biomarkers Prev 21:943-950, 2012

9. Craig BM, Donovan KA, Fraenkel L, Watson V, Hawley S, Quinn GP: A generation of childless women: lessons from the United States. Womens Health Issues 24:e21-e27, 2014

10. Fan Z, Ji T, Wan S, Wu Y, Zhu Y, Xiao F, et al: Smoking and risk of meningioma: a meta-analysis. Cancer Epidemiol 37:39-45, 2013

11. Galeone C, Malerba S, Rota M, Bagnardi V, Negri E, Scotti $\mathrm{L}$, et al: A meta-analysis of alcohol consumption and the risk of brain tumours. Ann Oncol 24:514-523, 2013

12. Groves RM, Mosher WD, Lepkowski J, Kirgis NG: Planning and development of the continuous National Survey of Family Growth. Vital Health Stat 1 (48):1-64, 2009

13. Isla A, Alvarez F, Gonzalez A, García-Grande A, PerezAlvarez M, García-Blazquez M: Brain tumor and pregnancy. Obstet Gynecol 89:19-23, 1997

14. Ives A, Saunders C, Bulsara M, Semmens J: Pregnancy after breast cancer: population based study. BMJ 334:194, 2007

15. Hu J, La Vecchia C, Negri E, Chatenoud L, Bosetti C, Jia X, et al: Diet and brain cancer in adults: a case-control study in northeast China. Int J Cancer 81:20-23, 1999

16. Johnson N, Sermer M, Lausman A, Maxwell C: Obstetric outcomes of women with intracranial neoplasms. Int J Gynaecol Obstet 105:56-59, 2009

17. Kanaan I, Jallu A, Kanaan H: Management strategy for meningioma in pregnancy: a clinical study. Skull Base 13:197203, 2003

18. Lagorio S, Röösli M: Mobile phone use and risk of intracranial tumors: a consistency analysis. Bioelectromagnetics 35:79-90, 2014
19. Lepkowski JM, Mosher WD, Davis KE, Groves RM, Van Hoewyk J: The 2006-2010 National Survey of Family Growth: sample design and analysis of a continuous survey. Vital Health Stat 2 (150):1-36, 2010

20. Lusis EA, Scheithauer BW, Yachnis AT, Fischer BR, Chicoine MR, Paulus W, et al: Meningiomas in pregnancy: a clinicopathologic study of 17 cases. Neurosurgery 71:951961, 2012

21. Monteiro GTR, Pereira RA, Koifman RJ, Koifman S: Head injury and brain tumours in adults: a case-control study in Rio de Janeiro, Brazil. Eur J Cancer 42:917-921, 2006

22. National Survey of Family Growth: NSFG 2006-08 Female Questionnaire, Female G CRQ, Year 1. Female Section G CAPI Reference Questionnaire (CRQ): Birth Desires and Intentions. Centers for Disease Control and Prevention. (http://www.cdc.gov/nchs/data/nsfg/NSFG_2006-2010_Y1_ FemaleG_CRQ.pdf) [Accessed November 5, 2014]

23. Qi ZY, Shao C, Huang YL, Hui GZ, Zhou YX, Wang Z: Reproductive and exogenous hormone factors in relation to risk of meningioma in women: a meta-analysis. PLoS ONE 8:e83261, 2013

24. Rajaraman P: Hunting for the causes of meningioma-obesity is a suspect. Cancer Prev Res (Phila) 4:1353-1355, 2011

25. Roelvink NC, Kamphorst W, August H, van Alphen M, Rao BR: Literature statistics do not support a growth stimulating role for female sex steroid hormones in haemangiomas and meningiomas. J Neurooncol 11:243-253, 1991

26. Schover LR, Rybicki LA, Martin BA, Bringelsen KA: Having children after cancer. A pilot survey of survivors' attitudes and experiences. Cancer 86:697-709, 1999

27. Vernooij MW, Ikram MA, Tanghe HL, Vincent AJ, Hofman A, Krestin GP, et al: Incidental findings on brain MRI in the general population. N Engl J Med 357:1821-1828, 2007

28. Whittle IR, Smith C, Navoo P, Collie D: Meningiomas. Lancet 363:1535-1543, 2004

29. Wiemels J, Wrensch M, Claus EB: Epidemiology and etiology of meningioma. J Neurooncol 99:307-314, 2010

30. Wiemels JL, Bracci PM, Wrensch M, Schildkraut J, Bondy M, Pfefferle J, et al: Assessment of autoantibodies to meningioma in a population-based study. Am J Epidemiol 177:7583,2013

31. Wiemels JL, Wrensch M, Sison JD, Zhou M, Bondy M, Calvocoressi L, et al: Reduced allergy and immunoglobulin $\mathrm{E}$ among adults with intracranial meningioma compared to controls. Int J Cancer 129:1932-1939, 2011

32. Wigertz A, Lönn S, Hall P, Auvinen A, Christensen HC, Johansen C, et al: Reproductive factors and risk of meningioma and glioma. Cancer Epidemiol Biomarkers Prev 17:2663-2670, 2008

33. Zhou P, Ma W, Yin S, Li Y, Jiang S: Three risk factors for WHO grade II and III meningiomas: a study of 1737 cases from a single center. Neurol India 61:40-44, 2013

\section{Author Contributions}

Conception and design: Craig, Reed. Acquisition of data: Craig, Owens. Analysis and interpretation of data: Craig. Drafting the article: all authors. Critically revising the article: all authors. Reviewed submitted version of manuscript: all authors. Approved the final version of the manuscript on behalf of all authors: Craig. Statistical analysis: Craig. Administrative/technical/material support: Owens. Study supervision: Craig, Reed.

\section{Correspondence}

Benjamin M. Craig, Moffitt Cancer Center, 12902 Magnolia Dr., MRC-CANCONT, Tampa, FL 33612. email: benjamin.craig@ moffitt.org. 